\title{
PEMAHAMAN DAN PARTISIPASI MASYARAKAT DALAM PENGELOLAAN EKOSISTEM MANGROVE DI PESISIR LAUT ARAFURA KABUPATEN MERAUKE
}

\section{Community Understanding and Participation to Mangrove Ecosystem Management in the Coastal Area of Arafura Sea, Merauke Districts}

\author{
${ }^{*}$ Maria M. D. Widiastuti ${ }^{1}$, Novel Ruata ${ }^{1}$ dan Taslim Arifin² \\ ${ }^{1}$ Universitas Musamus Merauke \\ Jl. Kamizaun Mopah Lama, Merauke 99600, Indonesia \\ ${ }^{2}$ Pusat Riset Kelautan, Badan Riset dan Sumber Daya Manusia Kelautan dan Perikanan \\ Kementerian Kelautan dan Perikanan, Indonesia \\ Diterima tanggal: 13 April 2018 Diterima setelah perbaikan: 219 Mei 2018 \\ Disetujui terbit: 18 Juni 2018 \\ "email: maria140379@gmail.com
}

\begin{abstract}
ABSTRAK
Ekosistem Mangrove mengalami tekanan dan penurunan jasa lingkungan diduga karena abrasi dan fenomena alam serta aktivitas masyarakat seperti penggalian pasir di pesisir pantai. Pemerintah telah melakukan upaya konservasi Mangrove dengan cara penanaman kembali, namun belum berhasil. Penelitian ini bertujuan untuk mengetahui pengetahuan masyarakat pesisir tentang Mangrove dan tingkat partisipasinya dalam pengelolaan ekosistem Mangrove dan perencanaan program rehabilitasi ekosistem Mangrove. Metode pengumpulan data menggunakan instrument pertanyaan berupa angket, observasi dan wawancara secara bersamaan dengan pola terstruktur baik dalam bentuk pertanyaan terbuka dan tertutup dan dianalisis secara deskriptif tabulatif. Penentuan sampel menggunakan sistem kuota dan pemilihan responden menggunakan simple random sampling. Hasil penelitian menyatakan 85 persen masyarakat pesisir paham terhadap pentingnya Mangrove bagi kehidupan mereka. Mereka paham bahwa Mangrove sebagai sumber mata pencaharian masyarakat pesisir dan pelindung pantai dari ombak dan abrasi. Mereka juga mengatakan bahwa Mangrove saat ini dalam keadaan kurang baik (53\%). Mereka mengaku terlibat aktif dalam kegiatan program penanaman Mangrove (43\%) namun bukan atas inisiatif sendiri. Kegiatan pelestarian Mangrove perlu melibatkan masyarakat setempat dalam bentuk pelatihan, penyuluhan atau pengawasan.
\end{abstract}

Kata Kunci: pengetahuan masyarakat; ekosistem mangrove; Pesisir Laut Arafura

\begin{abstract}
Ecosystem Mangrove had underpressure and decreasing environmental services because of abration as natural phenomena, and unsuistainable community activities such as sand mining. The Government has made the conservation of Mangrove by replanting, but has not succeeded. This study aims to determine community knowledge and participation in management ecosystem Mangrove for rehabilitation. The collecting datamethod use a questionnaire instrument, observations and interviews simultaneously with open and closed questions and analyzed in descriptive tabulative. The sample size using the quota method and the selection of respondents used the simple random sampling. The result showed that 85 percent of coastal communities understand the importance of Mangrove for their lives. They understand that Mangrove as a source of livelihood of coastal communities and coastal protection from waves and abrasion. They also said that the Mangrove is currently in a state of poor (53\%). They claimed active involved in Mangrove planting program (43\%), but not on their own initiative. The Mangrove conservation activities should be involvedby local community in such training, counseling or supervision.
\end{abstract}

Keywords: community knowledge; mangrove ecosystem; Arafura Coastal Area 


\section{PENDAHULUAN}

Ekosistem pesisir merupakan sumber daya penting dalam mendukung kehidupan manusia dan mahluk hidup yang tinggal di wilayah tersebut. Sumber daya pesisir yang melimpah dengan kualitas yang baik merupakan hal penting dalam proses biologis dan mendukung kehidupan mahluk hidup didalamnya, terlebih dalam hal keanekaragaman hayati (biodiversitas). Penyusutan keanekaragaman jenis terjadi baik pada populasi alami, maupun budidaya (Swaminathan, 1983). Fungsi sumber daya pesisir baik sebagai bahan produksi primer maupun turunannya banyak dibutuhkan oleh kehidupan manusia. Studi valuasi sumber daya pesisir sangat dibutuhkan untuk meningkatkan pengetahuan terhadap nilai sebuah ekosistem. Manfaat yang dihasilkan dari sebuah ekosistem seringkali dinilai terlalu rendah, hal inilah yang menyebabkan sumber daya pesisir mudah dirusak (Wattage, 2011).

Mangrove merupakan salah satu ekosistem pesisir yang memerlukan penanganan yang terpadu. Menurut Astirin (2000), prioritas pendekatannya adalah untuk memenuhi kebutuhan dasar manusia, memberikan sumber pendapatan dan mengembangkan lingkungan hidup yang sehat. Mangrove didefinisikan sebagai komunitas vegetasi pantai tropis yang didomonasi oleh beberapa jenis pohon mangrove yang mampu tumbuh dan berkembang pada daerah pasang surut pantai berlumpur. Mangrove merupakan tipe hutan tropika yang khas tumbuh di sepanjang pantai atau muara pantau yang dipengaruhi oleh pasang surut air laut mangrove banyak ditemukan dipantaipantai teluk yang dangkal, estuaria, delta dan daerah pantai yang terlindung. Mangrove tumbuh optimal di wilayah pesisir yang memiliki muara sungai besar dan bersubtrat lumpur, sedangkan di wilayah pesisir yang tidak terdapat muara sungai, hutan mangrove pertumbuhannya tidak optimal. Ini terbukti dari daerah penyebaran mangrove di Indonesia, yang umunya terdapat di Pantai Timur Sumatera, Kalimantan, Pantai Utara Jawa dan Irian Jaya (Bengen, 2002).

Kabupaten Merauke terletak di pesisir Selatan Arafura dan memiliki ekosistem Mangrove terluas di Papua. Berdasarkan data Badan Pengelolaan Lingkungan Hidup (Tim Bappesdalh Provinsi Papua, 2012) pada Tahun 2000, Tiga Kabupaten yang memiliki hutan Mangrove terluas yaitu Kabupaten Merauke, Asmat dan Mimika dengan luas berturut-turut 343.766, 305.172 dan
268.788 ha, namun perhitungan luas Mangrove pada tahun 2006 oleh Bapedalda Provinsi Papua ternyata mengalami penurunan rata-rata 6,71 persen/tahun. Menurut perhitungan Lembaga Swadaya Masyarakat (LSM) World Wild Fund (WWF), luas Mangrove di Kabupaten Merauke pun berkurang sebanyak $8,03 \%$ menjadi 316.157 ha. Berdasarkan perhitungan citra satelit Tahun 2010 yang dilakukan oleh organisasi tersebut (Tim WWF, 2011) luas Mangrove di Kabupaten Merauke kembali berkurang hingga tersisa 296.778 ha. Selain luasan Mangrove yang terus mengalami penurunan, data WWF tahun 2010 juga mencatat ternyata kerapatan Mangrove rata-rata per ha hanya 348 pohon. Menurut Kriteria Baku Kerusakan Mangrove yang dikeluarkan Kementerian Lingkungan Hidup, jika kerapatan < 1000 individu/ha, Mangrove dalam kategori rusak. Hal ini tentu saja merupakan masalah regional yang perlu mendapatkan perhatian serius dari berbagai pihak.

Luasan ekosistem Mangrove yang terus menurun dan rendahnya tingkat kerapatan Mangrove diduga karena abrasi dan fenomena alam serta aktivitas masyarakat yang mengancam kelestarian Mangrove. Menurut Ratini etal. (2016), faktor penyebab degradasi meliputi faktor ekonomi, pendidikan dan lemahnya pengawasan dari pihak yang berwenang. Maraknya penggalian pasir di pesisir pantai, penebangan Mangrove untuk dijadikan kayu bakar dan perumahan, dan rendahnya kesadaran masyarakat terhadap fungsi penting ekosistem ini mengancam manajemen pengelolaan pesisir. Hasil penelitian Jumaedi (2016), dilaporkan bahwa penyebab utama konversi ekosistem Mangrove di wilayah pesisir Kota Singkawang adalah tingginya kebutuhan ekonomi yang dibarengi dengan kurangnya kesadaran akan kepentingan ekologis serta kepedulian masyarakat pesisir akan dampak lingkungan. Rusaknya ekosistem ini berdampak buruk terhadap sejumlah masalah seperti tingkat abrasi yang tinggi, kerusakan rumah dan sarana jalan di pesisir pantai, menurunnya jumlah tangkapan udang dan kepiting dan masalah sosial ekonomi lain yang dirasakan oleh masyarakat. Menurut Arisandi (2014), telah terjadi penurunan rata-rata hasil tangkapan udang sebesar $5 \mathrm{~kg} /$ penjaring/hari. Abrasi yang hebat juga telah merusak sarana jalan dan jembatan di wilayah utara Merauke.

Pemerintah telah berupaya melakukan berbagai konservasi Mangrove dengan cara penanaman kembali. Namun upaya tersebut 
belum berhasil yang diperkirakan penyebabnya adalah kurang melibatkan masyarakat sekitar melalui pengetahuan dan pendidikan lingkungan. Penelitian ini bertujuan untuk mengetahui tingkat pemahaman masyarakat pesisir mengenai eksosistem Mangrove dan partisipasinya dalam kegiatan pengelolaan Mangrove. Hasil penelitian ini dapat menjadi dasar informasi bagi stakeholder yang melakukan program konservasi mangrove sehingga mampu menghasilkan dampak signifikan terhadap masyarakat sekitar dalam pengelolaan pesisir.

\section{METODOLOGI}

\section{Waktu dan Lokasi Penelitian}

Penelitian dilaksanakan pada bulan November 2015 di Kabupaten Merauke yang meliputi3 titik pengamatan yang mewakili wilayah pesisir Laut Arafura dari bagian selatan hingga utara. Ketiga titik tersebut meliputi: 1) Pantai Nasem yang berada di Distrik Naukenjerai, 2) Pantai Payum yang beradadi Distrik Merauke dan 3) Pantai Kumbe yang berada di Distrik Malind (Gambar 1).

\section{Data dan Sumber Data}

Data yang digunakan adalah data primer dan sekunder. Data sekunder diperoleh dari penelusuran literatur berupa jurnal dan pustaka lainnya. Data primer diperoleh dari wawancara dengan masyarakat yang berada di pesisir pantai Laut Arafura. Pengambilan data dilakukan dengan tehnik wawancara mendalam dengan menggunakan daftar pertanyaan terstruktur. Robinson (2000); Rachmawati (2007) menyatakan bahwa wawancara mendalam, formal terbuka merupakan aliran utama penelitian kualitatif. Responden diberikan sejumlah pertanyaan mengenai karakteristik, pemahaman tentang ekosistem Mangrove dan keterlibatannya dalam pelestarian Mangrove. Pengambilan sample masyarakat dilakukan secara non probability sampling dengan tehnik kuota sampling. Penentuan kuota berdasarkan sifat populasi masyarakat yang hampir homogen. Homogenitas populasi dilihat dari jenis pekerjaan masyarakat yang sebagian besar berprofesi sebagai nelayan (BPS, 2014). Hal tersebut menjadi dasar dalam penentuan kuota sampling yaitu 20 responden per titik pengamatan. Terdapat 3 titik pengamatan, sehingga total responden sebanyak 60 orang.

\section{Metode Analisis Data}

Data karakteristik responden, tingkat pemahaman, dan tingkat partisipasi responden dianalisis dengan metode analisis statistik deskriptif. Data ditabulasi kemudian dilakukan pengukuran pemusatan data seperti nilai mean dan median untuk setiap variabel pertanyaan. Mean merupakan pengukuran untuk meringkas sekelompok data dalam satu nilai tunggal yang spesifik dan terletak di tengah dari nilai-nilai pengamatan yang terhimpun dalam sekelompok data (Sugiyono, 2014). Pengukuran mean lebih peka terhadap nilai dan jumlah pengamatan sehingga lebih reliabel.

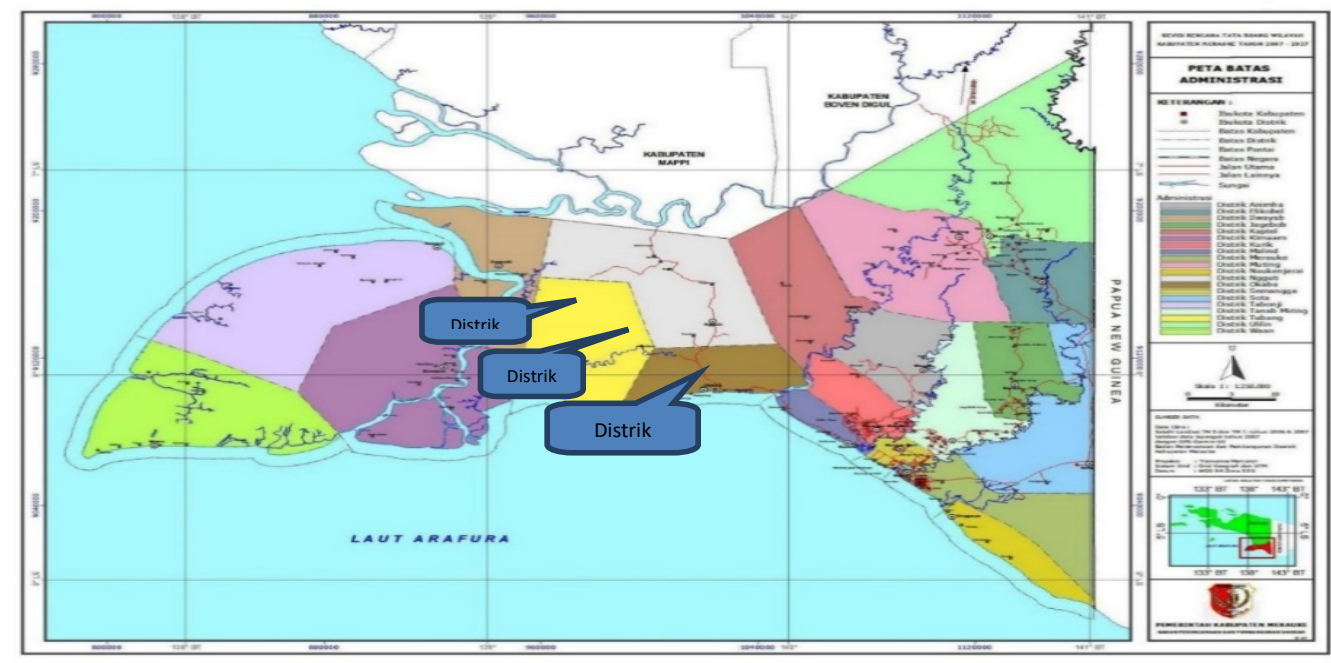

Gambar 1.Lokasi Pengambilan Data

Figure 1. Location Data Collection

Sumber: www.merauke.go.id)/Source: www.merauke.go.id 


\section{HASIL DAN PEMBAHASAN}

Responden diberikan sejumlah pertanyaan mengenai karakteristik, pemahaman tentang ekosistem Mangrove dan keterlibatannya dalam pelestarian Mangrove seperti di bawah ini.

\section{Karakteristik Responden}

\section{Jenis kelamin, Umur dan Status Perkawinan Responden}

Berdasarkan hasil rekapitulasi diperoleh 58 persen responden berjenis kelamin laki-laki dan perempuan 42 persen. Umur responden berada pada rentang usia produktif dengan rata-rata responden berusia 40 tahun. Adapun rentang umur responden secara rinci dapat dilihat pada grafik dibawah ini (Gambar 2). Sebanyak 29 responden berada pada rentang usia 20-35 tahun dan 16 responden berada di rentang usia 36-51 tahun, sebanyak 11 responden berada pada rentang usia tidak produktif. Rentang umur ini menunjukkan bahwa rumah tangga nelayan di Pesisir Laut Arafura masih termasuk umur produktif dan masih dapat ditingkatkan kapasitas dan kualitasnya.

Sebanyak $90 \%$ responden berstatus menikah dan 10\% responden belum menikah. Hal ini sesuai dengan umur responden yang sebagian besar berada pada rentang umur 20-51 tahun, sehingga dapat dipastikan bahwa sebagian besar responden sudah menikah (Gambar 3).

\section{Tingkat Pendidikan dan Pekerjaan Responden}

Dari hasil pengambilan data diperoleh tingkat pendidikan responden berkisar 58 persen berada pada level pendidikan dasar. Sebanyak 20 persen pada tingkat pendidikan SMP dan SMA (Gambar 4).

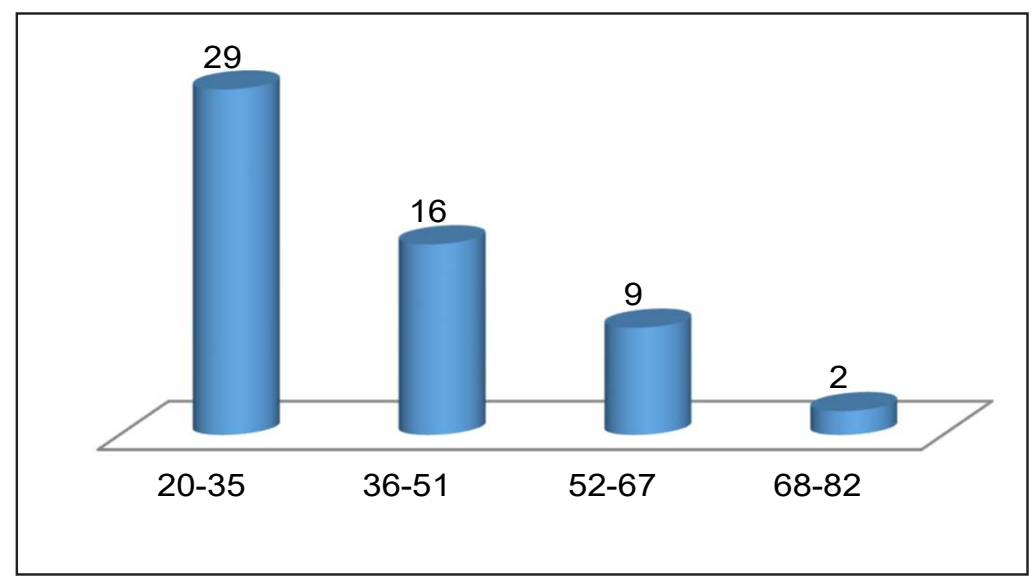

Gambar 2. Karakteristik Umur Responden.

Figure 2. Age Characteristics of Respondents.

Sumber: data primer diolah (2015)/Source: Primary Data Processed (2015)

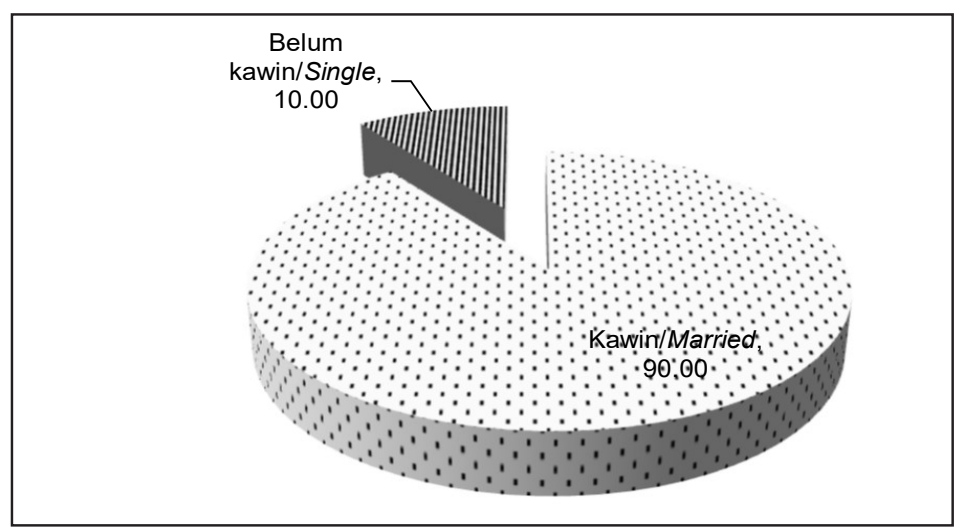

Gambar 3. Status Perkawinan Responden

Figure 3. Marital Status of Respondents.

Sumber: data primer diolah (2015)/Source: Primary Data Processed (2015) 


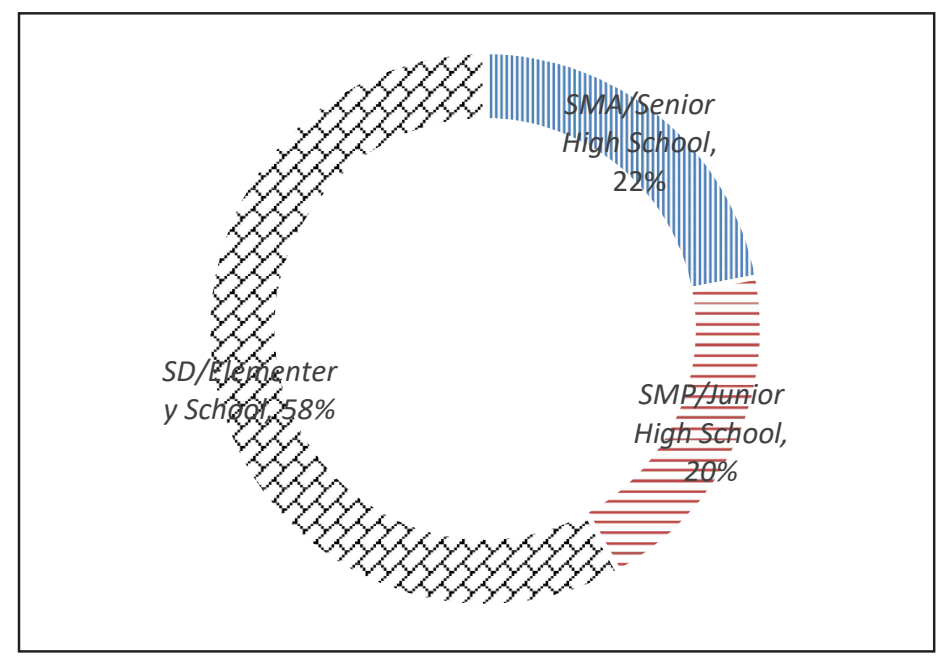

Gambar 4. Tingkat Pendidikan Responden.

Figure 4. Education Level of Respondents.

Sumber: data primer diolah (2015)/Source: Primary Data Processed (2015)

Tingkat pendidikan rumah tangga nelayan yang rendah merupakan tantangan terbesar dalam upaya meningkatkan pendapatan masyarakat pesisir maupun dalam meningkatkan pengetahuan terutama dalam program konservasi Mangrove. Untuk itu, diperlukan usaha ekstra dalam membangun masyarakat pesisir.

Survey ini dilakukan untuk masyarakat pesisir yang sebagian besar berprofesi sebagai nelayan. Wawancara dilakukan secara acak, ditemui adanya jenis pekerjaan yang lain. Hal tersebut menunjukkan bahwa mayoritas responden adalah nelayan yakni sebanyak 55 persen, 28 persen responden adalah ibu rumah tangga dan 5 persen adalah wiraswasta atau memiliki usaha kecil (Gambar 5).
Dari penelitian diperoleh hasil bahwa 68 persen responden memiliki pekerjaan sampingan. Hal ini menunjukkan bahwa pekerjaan utama nelayan belum dapat memberikan jaminan kesejahteraan bagi keluarga, sehingga sebagian besar memiliki alternatif usaha lain. Jenis pekerjaan utama yang mengandalkan sumber daya alam seperti petani, nelayan, dan penambang, memang memiliki resiko kerugian yang lebih tinggi dibandingkan jenis pekerjaan lain. Hal ini terjadi karena kelancaran usaha/pekerjaan tersebut sangat dipengaruhi oleh faktor eksternal yang sulit dikendalikan oleh manusia, contohnya cuaca/iklim, kondisi tanah, air dan sejenisnya. Dari hasil penelitian, jenis pekerjaan sampingan yang terbanyak dimiliki oleh responden terdapat pada Gambar 6.

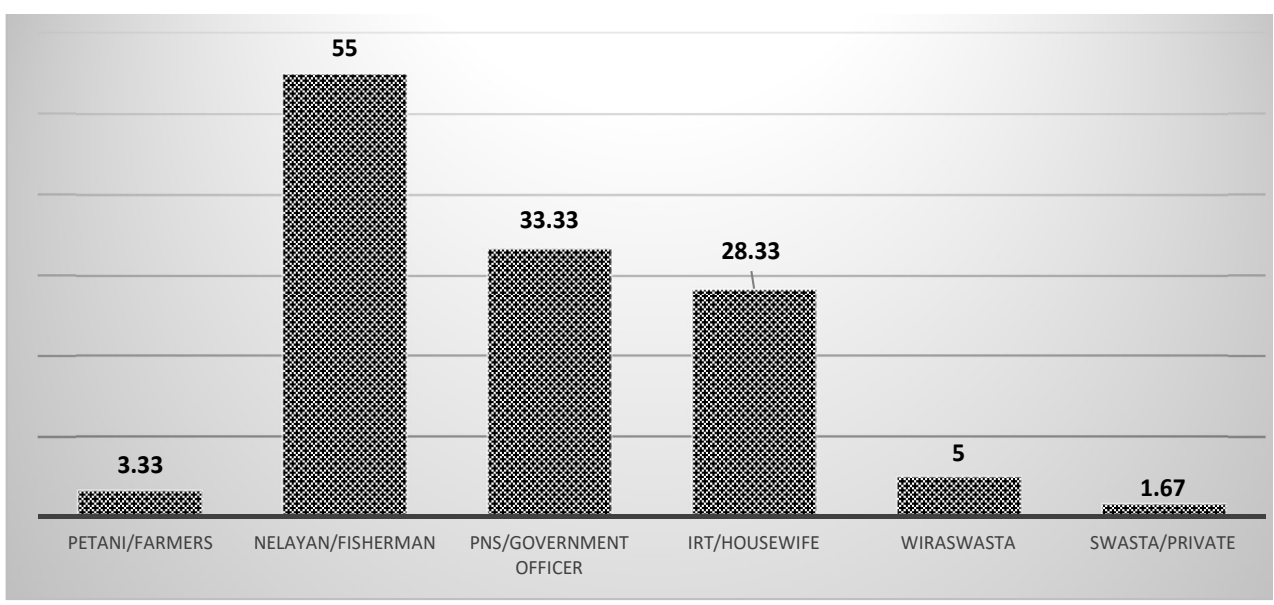

Gambar 5. Karakteristik Jenis Pekerjaan Responden.

Figure 5. Job Characteristics of Respondent.

Sumber: data primer diolah (2015)/Source: Primary Data Processed (2015) 


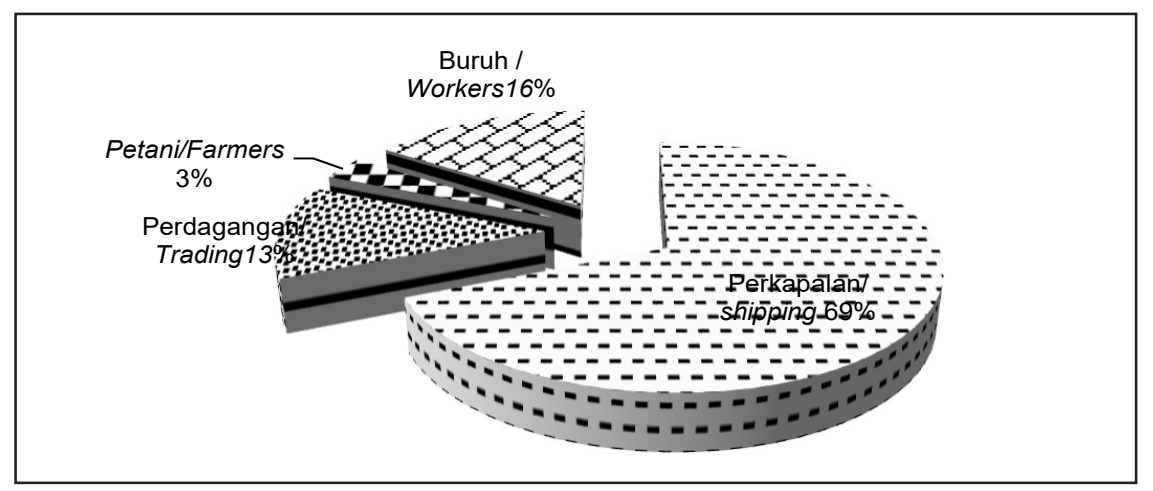

Gambar 6. Pekerjaan Sampingan Responden.

Figure 6. Side Jobs of Respondent.

Sumber: data primer diolah (2015)/Source:Primary Data Processed (2015)

Sebagian besar responden masih bekerja seputar bidang perikanan dan kelautan $(69 \%)$ seperti buruh kapal, juru mudi kapal, pembuat perahu, dan menjaring (Gambar 6). Profesi lainnya sebagai buruh bangunan sebanyak $16 \%$ dan perdagangan $13 \%$. Alternatif pekerjaan lain yaitu sebagai petani atau peternak.

\section{Jumlah Anggota Rumah Tangga dan Pendapatan Responden}

Rata-rata jumlah anggota rumah tangga nelayan yang berada di pesisir pantai Laut Arafura sebanyak 6 orang, hal itu berarti rata-rata nelayan memiliki 4 orang anak atau menampung sanak keluarga untuk tinggal dalam rumah tangga mereka. Jumlah keluarga yang besar pada rumah tangga nelayan ini tentunya menambah besarnya pengeluaran keluarga, sehingga pendapatan nelayan sebagian besar habis untuk konsumsi rumah tangga. Untuk pendapatan rumah tangga responden, dari hasil kuesioner diperoleh hasil rata-rata pendapatan rumah tangga responden sebesar Rp1.343.860,00. Sebanyak 18 responden memiliki penghasilan di bawah Rp500.000,-/ bulan; 17 responden berpenghasilan antara Rp500.000 - Rp1.000.000; dan hanya 1 orang yang berpenghasilan di atas Rp5.000.000,(Gambar 7).

\section{Pemahaman Tentang Ekosistem Mangrove}

Tingkat kepedulian dan kepentingan masyarakat terhadap ekosistem Mangrove dapat diketahui dengan memberikan sejumlah pertanyaan kepada responden dan diminta untuk melakukan penilaian terhadap pertanyaan tersebut. Adapun penilaian dibuat menggunakan skala likert dari 1 sampai 4 , dengan kategori "sangat penting", "cukup penting", "kurang penting" dan "tidak penting" (Likert (1932) dalam Budiaji (2013)).

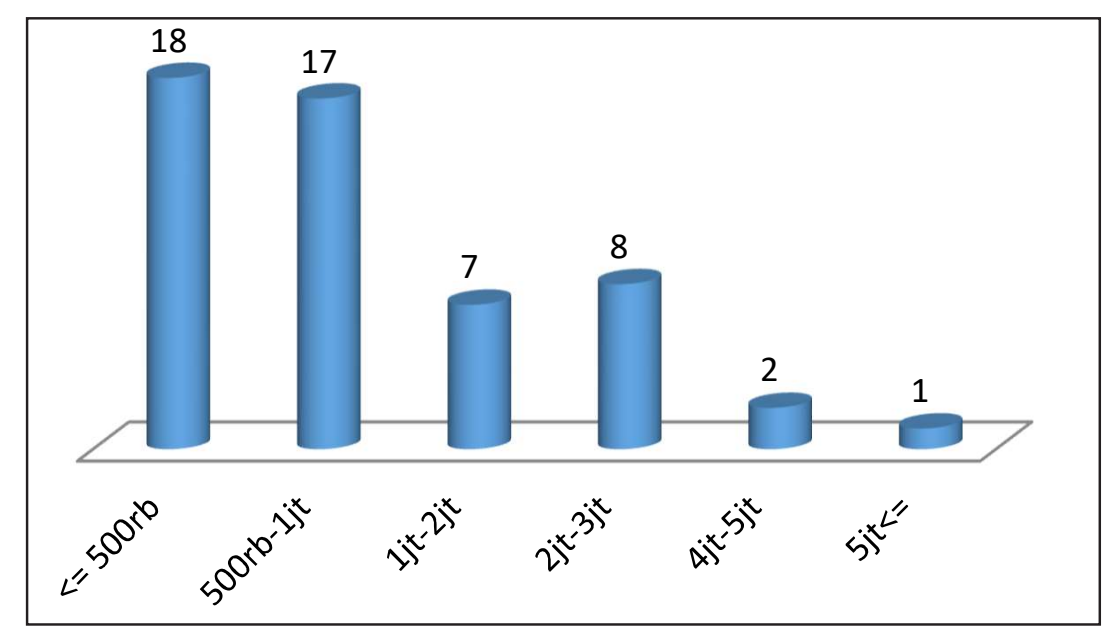

Gambar 7. Tingkat Pendapatan Rumah Tangga Nelayan. Figure 7. Income Level of Fisher's Household.

Sumber: data primer diolah (2015)/Source: Primary Data Processed (2015) 
Dari hasil pengumpulan data diperoleh 85 persen responden menyatakan bahwa Mangrove sangat penting bagi kehidupan masyarakat pesisir. Hanya dua responden yang mengatakan "cukup penting" dan satu responden mengatakan "tidak penting". Sebanyak 70\% menyatakan bahwa masyarakat "sering" beraktivitas di sekitar Mangrove, 25\% menyatakan "jarang" dan hanya $5 \%$ tidak pernah beraktivitas di Mangrove. Terkait dengan pengetahuan masyarakat mengenai fungsi ekosistem Mangrove, sebagian besar responden $(79 \%)$ tahu bahwa fungsi Mangrove adalah sebagai tempat sumber mata pencaharian masyarakat seperti menangkap ikan, udang, kepiting dan mengambil kayu bakar atau kayu bangunan. Fungsi Mangrove sebagai tempat tinggal hanya diketahui oleh $7 \%$ responden dan $6 \%$ responden yang mengetahui bahwa Mangrove berfungsi sebagai tempat perkembang-biakan hewan seperti udang, kepiting dan berbagai jenis ikan. Sebanyak 9\% mengatakan bahwa fungsi Mangrove sebagai penahan ombak, perlindungan pantai dan mencegah banjir (Tabel 1). Jika dibandingkan dengan tingkat pemahaman masyarakat di Tugurejo Semarang (Diarto et al., 2012), 100\% responden tahu bahwa Mangrove berfungsi sebagai pelindung pinggir pantai/sungai dari abrasi yang disebabkan gelombang laut. Begitupula 100\% responden tahu bahwa Mangrove sebagai tempat perkembangbiakan berbagai jenis ikan, udang, kerang dan kepiting. Fungsi Mangrove sebagai tempat untuk mencari kayu bakar dan ikan hanya $52 \%$. Perbandingan data ini menyatakan bahwa masyarakat di pesisir pantai Arafura lebih banyak menggantungkan hidupnya terhadap ekosistem Mangrove dibandingkan masyarakat di kota Semarang.
Hal ini sesuai dengan hasil verifikasi pada pertanyaan lanjutan mengenai: setujukah responden bahwa manfaat Mangrove adalah sebagai tempat hidup, tempat berkembang dan tempat memijah ikan? Mengenai jawaban ini sebanyak $50 \%$ responden menyatakan setuju dan ada $7 \%$ responden yang menyatakan tidak setuju. Begitupula untuk pertanyaan verifikasi mengenai: setujukah responden bahwa fungsi Mangrove adalah mencegah abrasi, menahan intrusi air laut, menahan badai dan gelombang dan mencegah bencana lainnya? Untuk pertanyaan verifikasi ini hampir $100 \%$ responden menyatakan setuju. Hal ini menunjukkan bahwa fungsi Mangrove yang diketahui oleh masyarakat hanyalah sebagai tempat mata pencaharian masyarakat dan untuk mencegah banjir serta abrasi pantai. Fungsi Mangrove sebagai tempat hidup ikan, berkembang biak dan pemijahan kurang banyak diketahui oleh masyarakat. Dilihat dari ketidak-konsistenan jawaban responden terkait fungsi tersebut,makahal ini menunjukkan bahwa hubungan sebab akibat antara sumber mata pencaharian masyarakat dengan mangrove sebagai ekosistem penunjang kehidupan berbagai biota laut tidak sepenuhnya dipahami masyarakat.

Dari hasil wawancara mendalam dengan beberapa tokoh masyarakat, diperoleh informasi untuk beberapa wilayah seperti di Payum (Distrik Merauke) dan Kampung Nasem (Distrik Naukenjerai) memang telah dilakukan kegiatan penyuluhan tentang fungsi ekosistem hutan Mangrove dari instansi pemerintah terkait dan LSM Lingkungan. Sehingga jika dibandingkan pemahaman masyarakat pesisir diantara ketiga distrik, memang terdapat perbedaan signifikan antara masyarakat yang pernah mendapat

Tabel 1. Pengetahuan Responden Mengenai Fungsi Mangrove.

Table 1. Knowledge of Respondents About the Function of Mangrove Forest.

\begin{tabular}{lcc}
\hline \multicolumn{1}{c}{\begin{tabular}{c}
\multicolumn{1}{c}{$\begin{array}{c}\text { Fungsi Mangrovel } \\
\text { Mangrove Function }\end{array}$} \\
Tempat tinggal/Feeding ground
\end{tabular}} & $\begin{array}{c}\text { Jumlah/ } \\
\text { Total }\end{array}$ & $\begin{array}{c}\text { Persentase/ } \\
\text { Percentage }\end{array}$ \\
\hline $\begin{array}{l}\text { Sumber mata pencaharian/ Source of livelihood } \\
\text { (menangkap ikan, udang, kepiting, mengambil kayu)/ } \\
\text { (catching fish, shrimp, crab, take the wood) }\end{array}$ & 5 & $7 \%$ \\
$\begin{array}{l}\text { Tempat perkembangbiakan hewan (udang, ikan, } \\
\text { kepiting) / Spawning ground (shrimp, fish, crab) }\end{array}$ & 55 & $79 \%$ \\
Lainnya / Others & 4 & $6 \%$ \\
\hline \multicolumn{1}{c}{ Total/Total } & 6 & $9 \%$ \\
\hline
\end{tabular}

Sumber: Data primer diolah (2015)/Source: Primary data processed (2015) 
penyuluhan dan yang tidak pernah mendapat penyuluhan. Pendapat masyarakat tentang kondisi hutan Mangrove saat ini sangat beragam. Ada yang menganggap bahwa hutan Mangrove dalam keadaan sangat baik (2\%), baik (38\%). Sebagian besar responden mengatakan bahwa kondisi hutan Mangrove dalam keadaan kurang baik (53\%) bahkan ada $2 \%$ responden mengatakan kondisi hutan Mangrove dalam keadaan rusak (Gambar 8 ).

Mengenai dampak kerusakan Mangrove, sebagian besar responden tahu bahwa rusaknya hutan Mangrove memberi dampak negatif bagi kehidupan masyarakat. Hal ini terlihat pada (Tabel 2), sebanyak 32\% masyarakat menganggap bahwa dampak negatif dari rusaknya Mangrove adalah hilangnya daerah perlindungan pantai; $26 \%$ hilangnya habitat ikan dan kepiting dan $19 \%$ pendapatan nelayan hilang. Pilihan jawaban "keindahan alam yang hilang" merupakan pilihan jawaban yang paling sedikit dipilih oleh responden, hanya 11 responden (10\%) yang memilih pilihan ini. Sisanya sebanyak $12 \%$ menjawab lainnya, yaitu banjir dan instrusi air laut.

Pemahaman masyarakat pesisir tentang pentingnya Mangrove bagi kehidupan mereka sangat baik. Masyarakat sudah mengerti arti penting Mangrove dan dampak dari kerusakan ekosistem tersebut. Hal ini tercermin juga dari jawaban responden tentang kegiatan pelestarian Mangrove, sebanyak 98,36\% responden mengatakan bahwa mereka setuju jika Mangrove dilestarikan dan $100 \%$ responden setuju jika dilakukan kegiatan konservasi/penanaman kembali Mangrove. Responden juga $100 \%$ setuju jika Mangrove ini lestari sehinggadapat membawa manfaat bagi masyarakat sekitar.

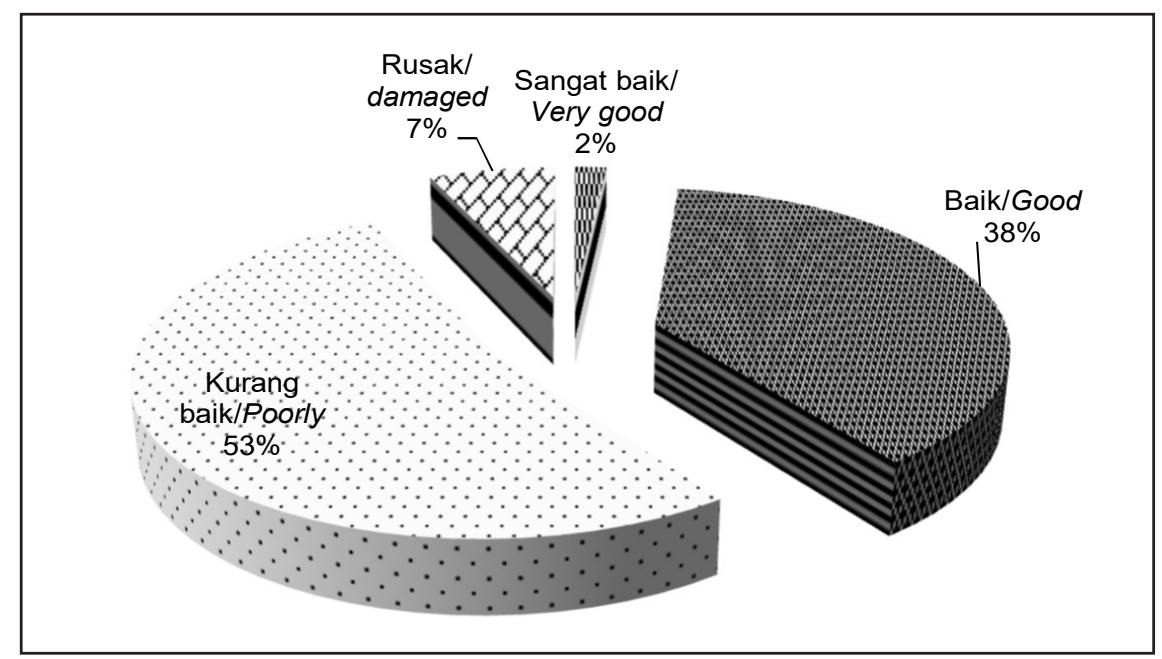

Gambar 8. Kondisi Mangrovemenurut Responden.

Figure 8. Perception Respondents of Mangrove Condition.

Sumber: Data primer diolah (2015)/Source: Primary data processed (2015)

Tabel 2. Jawaban Responden Mengenai Dampak Negatif Rusaknya Mangrove.

Table 2. Respondents Answer About Negative Impact Mangrove Damage.

\begin{tabular}{lcc}
\hline \multicolumn{1}{c}{$\begin{array}{c}\text { Dampak Negatif Rusaknya Mangrovel } \\
\text { Negative Impact of Mangrove Damage }\end{array}$} & $\begin{array}{c}\text { Jumlah/ } \\
\text { Total }\end{array}$ & $\begin{array}{c}\text { Persentase/ } \\
\text { Percentage }\end{array}$ \\
\hline $\begin{array}{l}\text { Hilangnya Habitat Ikan dan Kepiting/Loss of Fish } \\
\text { and CrabsHabitat }\end{array}$ & 28 & $26 \%$ \\
$\begin{array}{l}\text { Hilangnya Daerah Perlindungan Pantai/Loss of } \\
\text { Coastal Protection Area }\end{array}$ & 34 & $32 \%$ \\
$\begin{array}{l}\text { Pendapatan Nelayan Kurang/Less Fisher's Income } \\
\text { Keindahan Alam Menjadi Hilang/Loss of Beach }\end{array}$ & 20 & $19 \%$ \\
scenary & 11 & $10 \%$ \\
Lainnya/Others $\quad$ Total/Total & 13 & $12 \%$ \\
\hline
\end{tabular}

Sumber: Data primer diolah (2015)/Source: Primary data processed (2015) 


\section{Tingkat Partisipasi Masyarakat}

Partisipasi diartikan sebagai keikutsertaan atau keterlibatan masyarakat setempat dalam kegiatan pelestarian ekosistem Mangrove guna menjaga sumber daya pesisir tersebut agar tetaplestari. Untuk itu partisipasi masyarakat dalam kegiatan konservasi Mangrove sangat diharapkan. Adanya partisipasi masyarakat menjadi faktor pendukung dalam upaya pengembangan wilayah pesisir (Diarto et al., 2012). Gambaran partisipasi masyarakat terhadap pengelolaan lingkungan Mangrove ditunjukkan dengan tingginya keinginan masyarakat untuk menjaga dan melestarikan serta adanya harapan terhadap upaya perlindungan atau perbaikan ekosistem Mangrove. Bentuk partisipasi masyarakat adalah partisipasi sukarela atau swakarsa.

Hasil penelitian Safitri et al. (2012) terhadap tingkat partisipasi masyarakat pesisir dalam pelestarian Mangrove di Kabupaten Tanah Laut, dilaporkan bahwa tingkat partisipasi masyarakat secara keseluruhan pada tarap perencanaan berada pada kategori partisipasi rendahdengan skor rata-rata 4,17 $(27,8 \%)$. Lebih lanjut Gumilar (2012), program rehabilitasi Mangrove di Indramayu periode $1995-2009$, indeks partisipasi masyarakat sebesar 0,59. Artinya bahwa derajat partisipasi masyarakat dalam program rehabilitasi Mangrove masih rendah $(<1)$. Berbeda dengan laporan penelitian oleh Fitria (2015), yang menyatakan bahwa partisipasi masyarakat Kabupaten Cirebon dalam pengelolaan kawasan Mangrove cukup baik, terdapat kelompok pengawas Mangrove (Pokwasmas) yang sudah terlatih (Gambar 9).
Jawaban responden untuk pertanyaan berikut ini: "Apakah Bapak/lbu pernah mengikuti kegiatan pelestarian dan pengelolaan Mangrove (perencanaan, pelaksanaan dan evaluasi) yang difasilitasi oleh pemerintah dan lembaga?". Sebagian besar masyarakat (45\%) pernah terlibat dalam kegiatan pelestarian Mangrove, $1,67 \%$ mengaku "sering terlibat"; $43,3 \%$ mengaku "sering" dan $16 \%$ pernah terlibat namun tidak rutin (jarang). Sebanyak 38\% responen mengatakan "tidak pernah" ikut kegiatan konservasi Mangrove (Gambar 9). Jika dibandingkan antara tiga wilayah pengamatan terlihat bahwa responden di Pantai Kumbe $75 \%$ tidak pernah terlibat dalam kegiatan pelestarian Mangrove, sedangkan dua wilayah lain yaitu Kampung Nasem dan Payum, sebagian besar masyarakatnya sudah pernah ikut kegiatan pelestarian dalam rentang aktif sampai dengan jarang. Gambaran keterlibatan responden antara tiga wilayah pengamatan terlihat pada Tabel 3 .

Selain keterlibatan masyarakat dalam program konservasi Mangrove yang diinisiasi oleh pemerintah maupun lembaga swadaya masyarakat yang bergerak di bidang lingkungan, penelitian ini juga menganalisis sejauh mana masyarakat dengan kehendak sendiri melakukan kegiatan konservasi di lingkungan sekitar mereka. Hasil penelitian terlihat pada Tabel 4. Secara umum masyarakat di Tiga Kampung sangat kurang inisiatifnya dalam program konservasi hutan Mangrove, walaupun mereka tahu dan paham pentingnya hutan Mangrove bagi ekonomi masyarakat dan keamanan dari bencana. Masyarakat di Kampung Nasem dan Payum yang

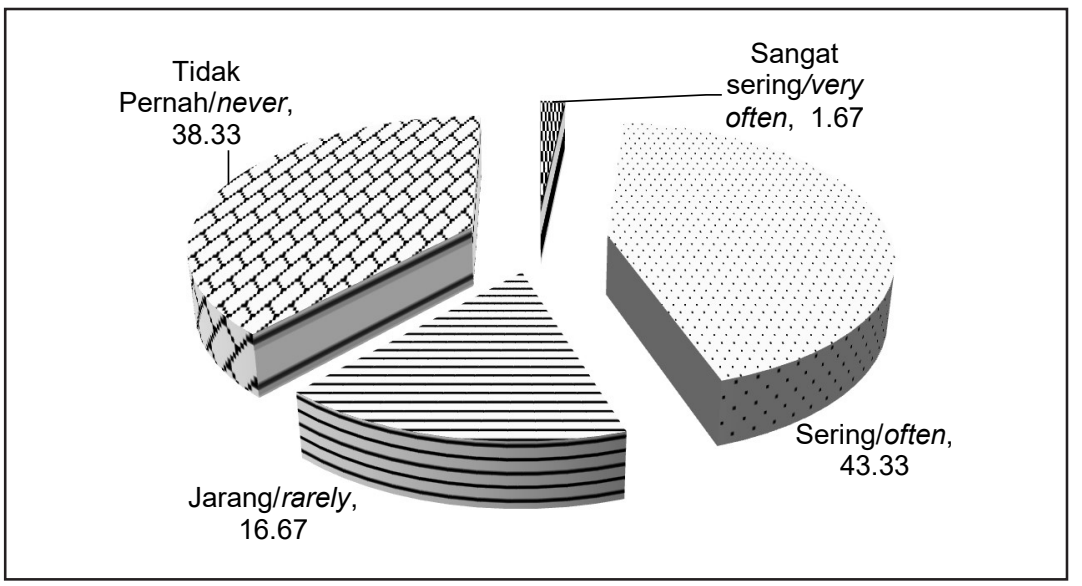

Gambar 9. Keterlibatan Masyarakat dalam Kegiatan Pelestarian Mangrove. Figure 9. Community Involvement in Mangrove Conservation Activities.

Sumber: Data primer diolah (2015)/Source: Primary data processed (2015) 
Tabel 3. Keterlibatan Masyarakat dalam Kegiatan Konservasi Mangrove.

Table 3. Community Involvement in Mangrove Conservation Activities.

\begin{tabular}{clccccc}
\hline $\begin{array}{c}\text { Nama Kampung/ } \\
\text { Name of the Village }\end{array}$ & $\begin{array}{c}\text { Sangat Sering/ } \\
\text { Very Often }\end{array}$ & $\begin{array}{c}\text { Sering/ } \\
\text { Often }\end{array}$ & $\begin{array}{c}\text { Jarang/ } \\
\text { Rarely }\end{array}$ & $\begin{array}{c}\text { Tidak Pernah/ } \\
\text { Never }\end{array}$ & $\begin{array}{c}\text { Total/ } \\
\text { Total }\end{array}$ \\
\hline Nasem & $\begin{array}{l}\text { Jumlah/Total } \\
\text { Persentase/ }\end{array}$ & 1 & 9 & 6 & 4 & 20 \\
Percentage (\%) & 5 & 45 & 30 & 20 & 100 \\
Payum & $\begin{array}{l}\text { Jumlah/Total } \\
\text { Kersentase/ }\end{array}$ & 0 & 13 & 3 & 4 & 20 \\
& $\begin{array}{l}\text { Percentage (\%) } \\
\text { Jumlah/Total }\end{array}$ & 0 & 65 & 15 & 20 & 100 \\
\hline \multirow{2}{*}{$\begin{array}{l}\text { Persentase/ } \\
\text { Rata-rata/ Average }\end{array}$} & 0 & 4 & 1 & 15 & 20 \\
Persentase/ Percentage (100\%) & 0 & 20 & 5 & 75 & 100 \\
\hline
\end{tabular}

Sumber: Data primer diolah (2015)/Source: Primary data processed (2015)

pernah mendapatkan pelatihan maupun program penanaman Mangrove dari pemerintah maupun lembaga lain ternyata sangat kurang inisiatifnya dalam melakukan kegiatan konservasi secara swadaya, sedangkan di Kampung Kumbe yang berdasarkan hasil wawancara belum pernah mendapatkan penyuluhan maupun program penanaman Mangrove ternyata ada (20\%) yang melakukan kegiatan penanaman Mangroveatas kehendak sendiri. Hal ini kemungkinan karena tingkat pendidikan masyarakat yang lebih tinggi dibandingkan dua desa yang lain. Struktur masyarakat di Kumbe juga lebih heterogen dibandingkan Payum dan Nasem yang memiliki struktur masyarakat hampir homogen.

Terkait program konservasi Mangrove, Nurrani etal. (2015), melaporkan bahrwa partisipasi tokoh masyarakat, peneliti mancanegara, NGO/
LSM, Pemerintah desa, lembaga keagamaan dan lembaga pendidikan formal merupakan aspek penting yang menjadi pilar utama dan kunci keberhasilan dalam rehabilitasi hutan Mangrove di Desa Tiwoho Sulawesi Utara.

Walaupun tingkat inisiatif masyarakat untuk kegiatan pelestarian Mangrove relative rendah, namun $43,3 \%$ responden sepakat bahwa masyarakat harus dilibatkan dalam program pelestarian Mangrove. Sebanyak 41,67\% responden setuju jika pemerintah melakukan program pembinaan kepada masyarakat melalui penyuluhan dan pelatihan agar dapat berpartisipasi terhadap pelestarian Mangrove. Keterlibatan masyarakat juga dalam bentuk pengawasan, karena $58 \%$ responden setuju hutan Mangrove ini perlu diawasi supaya tetap lestari.

Tabel 4. Inisiatif Masyarakat dalam Melakukan Penanaman Mangroveatas Kehendak Sendiri. Table 4. Community Initiative to Plant Mangrove by Their Own.

\begin{tabular}{|c|c|c|c|c|c|c|}
\hline $\begin{array}{c}\text { Nama Kampung/ } \\
\text { Name of the } \\
\text { Village }\end{array}$ & & $\begin{array}{l}\text { Sangat sering/ } \\
\text { very Often }\end{array}$ & $\begin{array}{l}\text { Sering/ } \\
\text { Often }\end{array}$ & $\begin{array}{c}\text { Jarang / } \\
\text { Rarely }\end{array}$ & $\begin{array}{c}\text { Tidak Pernah/ } \\
\text { Never }\end{array}$ & $\begin{array}{l}\text { Total/ } \\
\text { Total }\end{array}$ \\
\hline \multirow[t]{2}{*}{ Nasem } & Jumlah/Total & 0 & 1 & 0 & 19 & 20 \\
\hline & $\begin{array}{l}\text { Persentase/ } \\
\text { Percentage (\%) }\end{array}$ & 0 & 5 & 0 & 95 & 100 \\
\hline \multirow[t]{2}{*}{ Payum } & Jumlah/Total & 0 & 0 & 5 & 15 & 20 \\
\hline & $\begin{array}{l}\text { Persentase/ } \\
\text { Percentage (\%) }\end{array}$ & 0 & 0 & 25 & 75 & 100 \\
\hline \multirow[t]{2}{*}{ Kumbe } & Jumlah/Total & 1 & 3 & 2 & 14 & 20 \\
\hline & $\begin{array}{l}\text { Persentase/ } \\
\text { Percentage (\%) }\end{array}$ & 5 & 15 & 10 & 70 & 100 \\
\hline \multicolumn{2}{|c|}{ Jumlah/Total } & 0.3 & 1.3 & 2.3 & 16 & 20 \\
\hline \multicolumn{2}{|c|}{ Persentase/ Percentage (\%) } & 1.7 & 6.7 & 11.7 & 80 & 100 \\
\hline
\end{tabular}

Sumber: Data primer diolah (2015)/Source: Primary data processed (2015) 


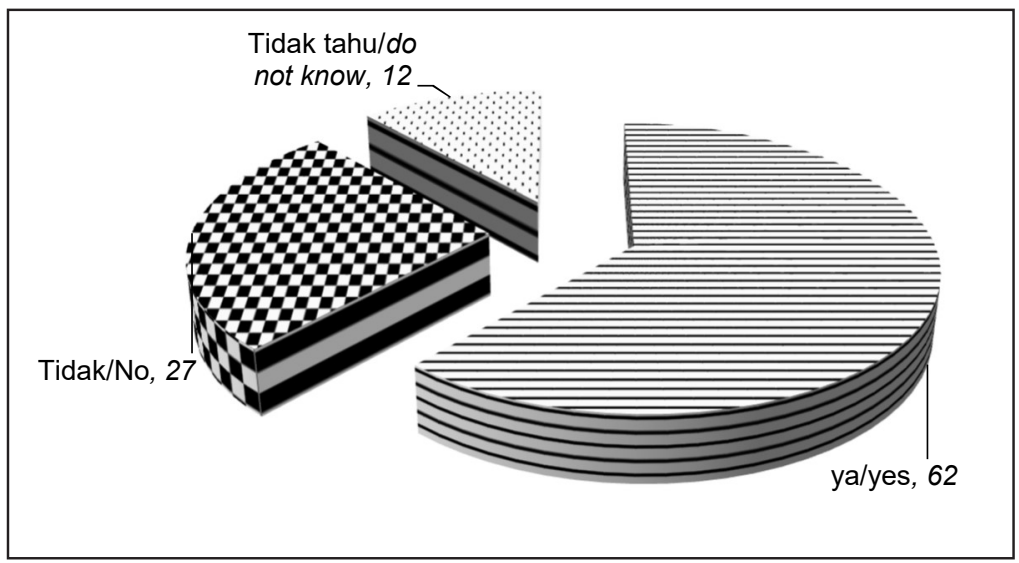

\section{Gambar 10. Pengetahuan Masyarakat Tentang Keberadaan Peraturan Kampung. Figure 10. Community Knowledge about Village Regulation.}

Sumber: Data primer diolah (2015)/Source: Primary data processed (2015)

Dalam hal pengawasan sebagai bentuk kearifan lokal masyarakat, ternyata $62 \%$ responden mengatakan bahwa ada peraturan kampung yang mengatur tentang pengawasan dan pemanfaatan Mangrove, $27 \%$ responden mengatakan tidak ada peraturan kampung dan $12 \%$ mengatakan tidak tahu apakah ada peraturan kampung tentang Mangrove (Gambar 10). Hasil penelitian Madiama et al. (2016), persepsi masyarakat terhadap upaya pelestarian mangrove yang dianalisis berdasarkan skala pengetahuan, sikap dan tindakan. Dalam hal ini tingkat pengetahuan masyarakat termasuk dalam kategori tinggi yaitu mencapai angka $26.70 \%$, sedangkan tingkat sikap masyarakat juga termasuk dalam kategori tinggi yaitu mencapai angka $31.10 \%$.

Walaupun sebagian responden menyatakan ada peraturan kampung namun mereka tidak bisa menyebutkan apa saja peraturan kampung tersebut. Terdapat 2 (Dua) orang responden dari Kumbe yang menyatakan bahwa ada peraturan kampung untuk tidak boleh menebang kayu mangrove tanpa ijin kepada kepala dusun. Ada pula responden dari Nasem yang menyatakan bahwa peraturan kampung tentang Mangrove masih dalam tahap pembahasan dengan warga masyarakat dan belum diputuskan.

Responden yang menjawab ada peraturan di kampung tentang pelestarian dan pemanfaatan mangrove, pertanyaan selanjutnya adalah apakah responden setuju dengan peraturan tersebut? $62 \%$ responden mengatakan setuju terhadap peraturan tersebut.

Pemahaman masyarakat tentang peraturan daerah mengenai pelestarian dan pemanfaatan Mangrove, sebanyak 48,33\% responden mengatakan bahwa pemerintah daerah memiliki peraturan perundang-undangan tentang Mangrove, $18,33 \%$ mengatakan tidak punya peraturan dan $33,3 \%$ tidak tahu apakah pemerintah daerah memiliki peraturan tentang Mangrove. Ketika responden ditanya apa jenis peraturan yang dibuat oleh pemerintah, hampir sebagian besar mengatakan tidak tahu dan tidak bisa menyebutkan apa saja peraturan tersebut. Hanya 2 (Dua) orang yang mengatakan tidak boleh menebang pohon Mangrove. Dari responden yang mengatakan bahwa pemerintah memiliki peraturan tentang Mangrove, pertanyaan selanjutnya adalah apakah responden setuju dengan peraturan tersebut? $70,27 \%$ responden setuju dengan peraturan tersebut; $11 \%$ tidak setuju dan $2,7 \%$ tidak tahu.

Dari hasil penelitian mengenai partisipasi masyarakat dapat dijelaskan bahwa masyarakat sudah cukup paham mengenai arti penting ekosistem Mangrove bagi kehidupan masyarakat baik secara langsung maupun tidak langsung. Mereka pun memahami bahwa perlu ada peraturan baik di kampung maupun di daerah untuk menjaga kelestarian Mangrove. Terkait dengan tersebut, Raharjo et al. (2015), melaporkan bahwa upaya untuk menekan sekecil mungkin kerusakan adalah kerjasama antar pemerintah daerah, instansi terkait dan masyarakat. Walaupun tingkat partisipasi mereka secara inisiatif rendah dalam hal kegiatan konservasi/penanaman Mangrove, namun mereka setuju bahwa masyarakat perlu dilibatkan dalam program pelestarian Mangrove melalui kegiatan pelatihan/penyuluhan dan pengawasan. 


\section{KESIMPULAN DAN IMPLIKASI KEBIJAKAN}

\section{Kesimpulan}

Sekitar $85 \%$ masyarakat di wilayah pesisir Laut Arafura, yaitu masyarakat Pantai Nasem, Payum dan Kumbe, telah paham tentang pentingnya ekosistem mangrove bagi kehidupan mereka. Masyarakat memahami bahwa mangrove sebagai sumber mata pencaharian masyarakat pesisir dan pelindung pantai dari ombak dan abrasi. Masyarakat menyadari bahwa ekosistem mangrove saat ini dalam kondisi kurang baik, mereka terlibat aktif dalam kegiatan program penanaman mangrove, namun bukan atas inisiatif sendiri.

Saran untuk pengembangan penelitian lebih lanjut adalah dengan melihat pengaruh dan hubungan sebab akibat antara tingkat pemahaman dan partisipasi masyarakat dengan karakteristik masyarakat sehingga dapat memberikan informasi yang komprehensif mengenai perilaku masyarakat untuk mendukung program konservasi pesisir.

\section{Implikasi Kebijakan}

Pemahaman tentang ekosistem mangrove menunjukkan perbedaan yang signifikan antara masyarakat yang pernah mendapat penyuluhan dan yang tidak/belum pernah mendapat penyuluhan. Dengan demikian, dalam perencanaan kebijakan mengenai pengelolaan pesisir sebaiknya pemerintah daerah harus melibatkan masyarakat terutama tokoh adat dalam merencanakan program pengelolaan pesisir. Ketua adat atau tokoh masyarakat yang menggantungkan hidupnya pada ekosistem mangrove harus dapat mengajak dan mempengaruhi masyarakat serta memberikan contoh yang baik dalam mengelola ekosistem mangrove.

Tahapan implementasi dapat dilakukan dengan mengadakan kegiatan pelatihan, penyuluhan serta pengembangan kapasitas masyarakat untuk melakukan pengawasan terhadap program pengelolaan pesisir. Implementasi perencanaan harus segera dilakukan mengingat masih kurangnya inisiatif masyarakat tentang program konservasi mangrove, walaupun mereka sudah paham akan pentingnya mangrove bagi kehidupan mereka.

Kegiatan evaluasi dapat dilakukan dengan melibatkan masyarakat terutama tokoh adat dan tokoh kampung yang bersama-sama membuat perencanaan program pengelolaan pesisir, agar dapat ditarik benang merah dari setiap kegiatan/ program dan menjadi pembelajaran bagi program pengelolaan pesisir selanjutnya. Pendampingan kepada masyarakat merupakan hal yang penting dan harus terus dilakukan secara berkelanjutan.

\section{UCAPAN TERIMA KASIH}

Tulisan ini merupakan bagian dari roadmap penelitian pengelolaan pesisir melalui program pengelolaan ekosistem Mangrove yang berkelanjutan, tahun 2017. Ucapan terima kasih kepada Novel Ruata, MSi, Jurusan MSP FAPERTA-Universitas Musamus, atas diskusi dan masukannya dalam memperkaya tulisan ini.

\section{DAFTAR PUSTAKA}

Arisandi, H. S. 2014. Eksternalitas Penambangan Pasir Pantai Secara Tradisonial Terhadap Ekosistem Mangrove dan Sosial Ekonomi Masyarakat Pesisir di Kabupaten Merauke. Manajemen Perikanan dan Kelautan, Vol 1 (1): 1-10.

Astirin, O.P. 2000. Permasalahan Pengelolaan Keanekaragaman Hayati di Indonesia. BIODIVERSITAS, Vol1 (1): 36-40.

Badan Pusat Statistik Kabupaten Merauke. 2014. Merauke Dalam Angka . Merauke: BPS.

[BAPESDALH] Badan Perencanaan dan Pengelolaan Sumberdaya Alam dan Lingkungan Provinsi Papua. 2012. Buku I Menuju Indonesia Hijau Propinsi Papua. Jayapura: Bappeda Propinsi Papua.

Bengen, D. 2002. Pengenalan dan Pengelolaan Ekosistem Mangrove. Bogor: PKSPL - IPB.

Budiaji, W. 2013. Skala Pengukuran dan Jumlah Respon Skala Likert. Jurnal IImu Pertanian dan Perikanan. Vol 2(2): 127-133.

Diarto, Hendrarto. dan Suryoko. 2012. Partisipasi Masyarakat dalam Pengelolaan Lingkungan Kawasan Hutan Mangrove Tugurejo di Kota Semarang. Jurnal IImu Lingkungan. Vol 10 Issue 1:1-7.

Fitria, E. 2015. Analisis Persepsi dan Partisipasi Masyarakat Pesisir dalam Pemanfaatan Tumbuhan Mangrove Sebagai Pangan Alternatif untuk Menghadapi Ketahanan Pangan. Scientiae Educatia. Vol5 (2): 1 - 14.

Gumilar, I. 2012. Partisipasi masyarakat Pesisir dalam Pengelolaan Ekosistem Hutan Mangrove Berkelanjutan di Kabupaten Indramayu. Jurnal Akuatika Vol 3(2): 198-211. 
Jumaedi, S. 2016. Nilai Manfaat Hutan Mangrove dan Faktor-Faktor Penyebab Konversi Zona Sabuk Hijau (Greenbelt) Menjadi Tambak di Wilayah Pesisir Kota Singkawang Kalimantan Barat. Sosiohumaniora, Vol18 (3): $227-234$.

Madiama, S., C. Muryani dan S. Santoso. 2016. Kajian Perubahan Luas dan Pemanfaatan Serta Persepsi Masyarakat Terhadap Pelestarian Hutan MangrovediKecamatan Teluk Ambon Baguala. Jurnal Geo Eco Vol 2 (2): 170-183.

Nurrani, L., Bismark, M., Tabba, S. 2015. Partisipasi Lembaga dan Masyarakat dalam Konservasi Mangrove (Studi Kasus di desa Tiwoho Propinsi Sulawesi Utara). Jurnal WASIAN Vol. 2 No. 1 Tahun 2015: 21-32.

Rachmawati, I.N. 2007. Pengumpulan Data dalam Penelitian Kualitatif: Wawancara Pengumpulan Data dalam Penelitian Kualitatif: Wawancara. Jurnal Keperawatan Indonesia. Vol11 (1): 35-40.

Raharjo, P, D. Setiady, S. Zallesa dan E. Putri. 2015. Identifikasi Kerusakan Pesisir Akibat Konversi Hutan Bakau (Mangrove) Menjadi Lahan Tambak di Kawasan Pesisir Kabupaten Cirebon. Jurnal Geologi Kelautan. Vol13 (1): 9-24.

Ratini, B. S. dan T. Budiarti. 2016. Perencanaan Konservasi Ekosistem Mangrove Desa Ujung Alang Kecamatan Kampung Laut Kabupaten Cilacap. Jurnal Silvikultur Tropika. Vol07 (2): 108-114.

Robinson, J.P., 2000. Phases of the Qualitative Research Interview with Institutionalized Elderly Individuals. Journal of Gerontological Nursing. Vol 26(11); 1-17.

Safitri, N.H., T. Hidayat, R. Yunita, dan E. D. Pujawati. 2012. Partisipasi Masyarakat Pesisir Terhadap Kelestarian Hutan Mangrove (Studi Kasus Di Desa Kuala Tambangan Kecamatan Takisung Kabupaten Tanah Laut). EnviroScienteae. Vol 8: 154-163.

Sugiyono. 2014. Statistika untuk Penelitian. Bandung: Alfabeta.

Swaminathan. M S. 1983. The Miracle of Rice. The Courier. (December 1984): 4-8

Wattage, P. 2011. Valuation of Ecosystem Services in Coastal Ecosystems: Asian and European Perspectives. United Nation Enviromental Program, Ecosystem Services Economics. Nairobi: UNON.

World Wild Fund [WWF]. 2011. Annual Report. Merauke: WWF Region Sahul Papua. 